\title{
An unusual cause of right heart dilatation
}

\author{
Yiying Han*, Bao Ru Leong, Yi-Hui Hung, Alicia Er, Yunyun Go, Tiong Keng Lim \\ From 19th Annual SCMR Scientific Sessions \\ Los Angeles, CA, USA. 27-30 January 2016
}

\section{Background}

60 year-old lady with no significant medical history of note presented with shortness of breath on exertion for the past 3 months. Physical examination revealed a loud ejection systolic murmur at the left sternal edge. A transthoracic echocardiogram showed turbulent flow and increased velocity at the right ventricular outflow tract (RVOT). The right atrium and ventricle were dilated and there was severe tricuspid regurgitation (Figure 1). A cardiac MRI was ordered to ascertain the cause of RVOT obstruction.

\section{Results}

There is a large mass causing near occlusion of the main PA. This mass extends distally into proximal left and right PA. This mass also extends proximally into pulmonary valve and proximal posterior aspect of the RV out flow tract.

On T1W images, the tumor shows heterogeneous low-signal while on $\mathrm{T} 2 \mathrm{~W}$ sequences, it exhibits a mixed signal with hyperintensity as well as areas of intermediate to low intensity (Figure 2). The lack of T1 hyperintensity would be against a diagnosis of thrombus.

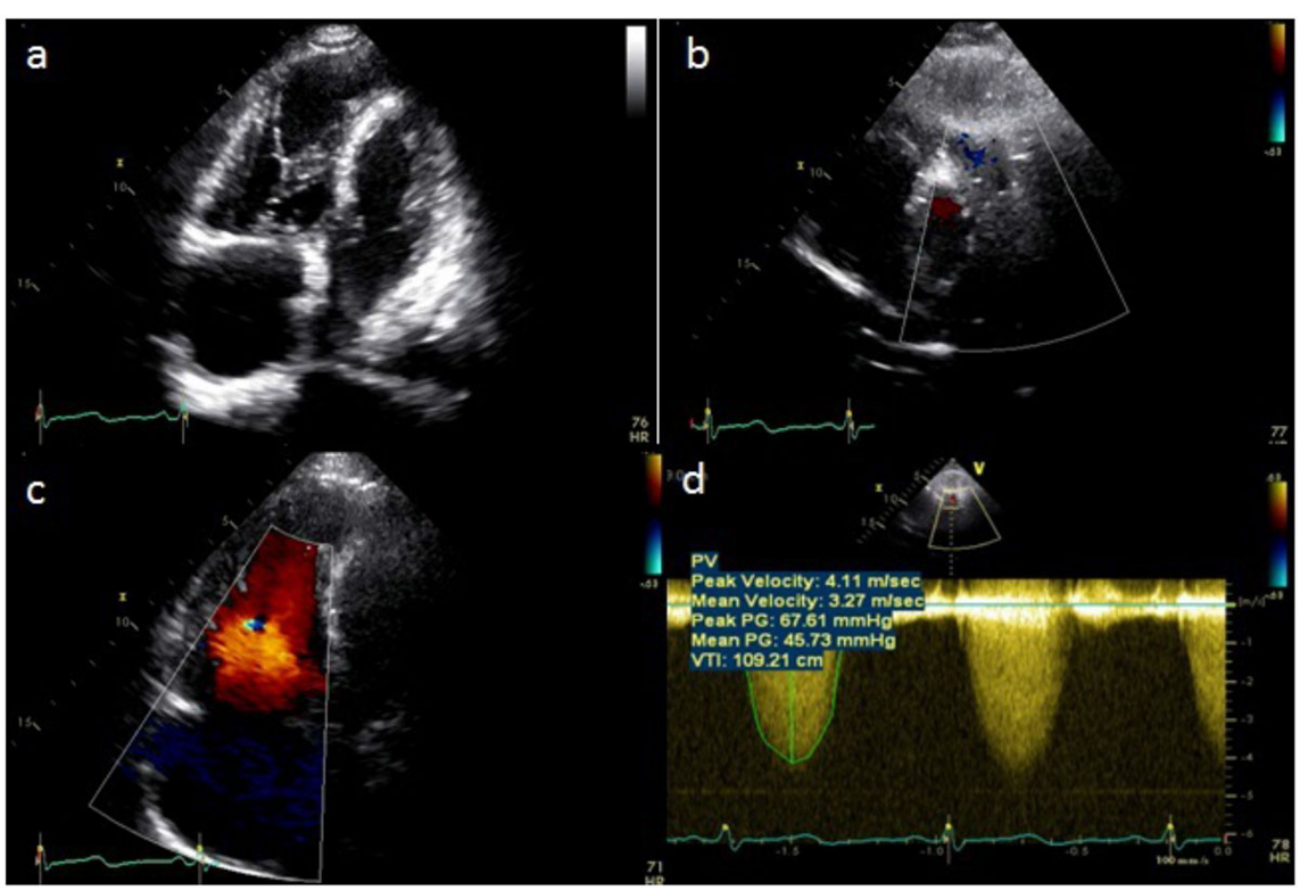

Figure 1 a. 4-chamber view, b. RVOT view, c. 4-chamber with color Doppler, d. CW Doppler at RVOT.

National Heart Centre Singapore, Singapore, Singapore

(C) 2016 Han et al. This is an Open Access article distributed under the terms of the Creative Commons Attribution License (http:// 


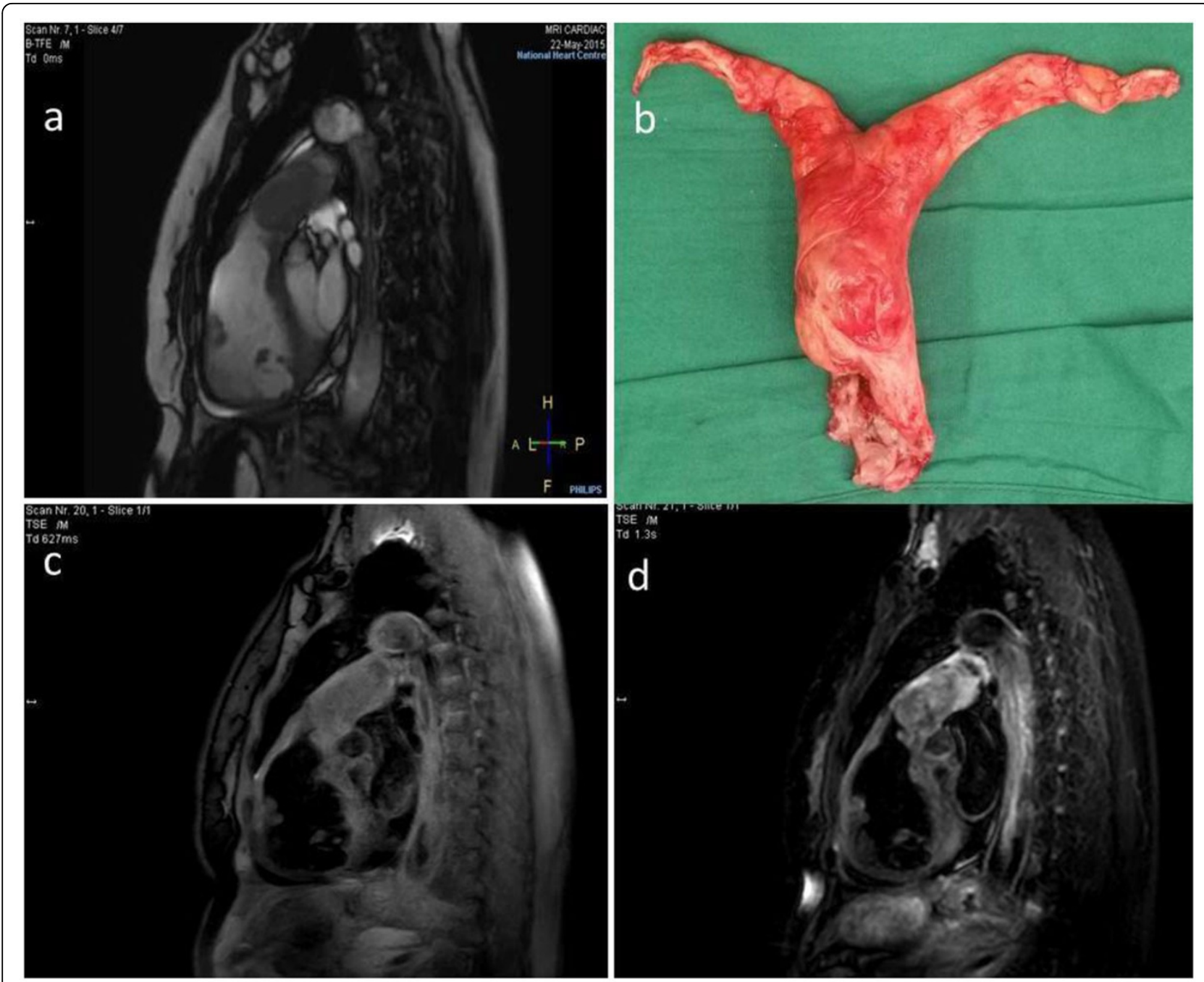

Figure 2 a. RVOT view, b. Specimen showed PA sarcoma resected en-bloc, c. T1 TSE fat sat, d. T2 TSE STIR.

\section{Conclusions}

The patient underwent complete endarterectomy, pulmonary valve replacement and PA reconstruction using a bifurcated Gelweave graft. She recovered well and was discharged home subsequently. Histology showed intimal sarcoma with focal myofibroblastic differentiation.

Pulmonary artery sarcomas are exceedingly rare. Other important and more common differential diagnoses to be considered include pulmonary embolism (PE) or tumor embolism from pulmonary or other malignancies. Pulmonary artery sarcoma mimicking as PE, pulmonary artery aneurysm or Takayasu's disease has been reported in the literature. In our case, the absence of thromboembolism risk factors, together with heterogeneous tumor enhancement and invasion into the wall of main pulmonary artery as well as its branches are suggestive of a malignant process instead of PE.
Published: 27 January 2016

doi:10.1186/1532-429X-18-S1-T4

Cite this article as: Han et al:: An unusual cause of right heart dilatation. Journal of Cardiovascular Magnetic Resonance 2016 18(Suppl 1):T4.

\section{Submit your next manuscript to BioMed Central} and take full advantage of:

- Convenient online submission

- Thorough peer review

- No space constraints or color figure charges

- Immediate publication on acceptance

- Inclusion in PubMed, CAS, Scopus and Google Scholar

- Research which is freely available for redistribution 